\title{
Small Engines as Bottoming Cycle Steam Expanders for Internal Combustion Engines
}

\author{
Rohitha Weerasinghe and Sandra Hounsham \\ Department of Engineering, Design and Mathematics, University of the West of England, Coldharbour Lane, Bristol BS16 1QY, UK \\ Correspondence should be addressed to Rohitha Weerasinghe; sujithrohitha@yahoo.com
}

Received 16 January 2017; Revised 4 April 2017; Accepted 20 April 2017; Published 31 May 2017

Academic Editor: Paul Hellier

Copyright (C) 2017 Rohitha Weerasinghe and Sandra Hounsham. This is an open access article distributed under the Creative Commons Attribution License, which permits unrestricted use, distribution, and reproduction in any medium, provided the original work is properly cited.

\begin{abstract}
Heat recovery bottoming cycles for internal combustion engines have opened new avenues for research into small steam expanders (Stobart and Weerasinghe, 2006). Dependable data for small steam expanders will allow us to predict their suitability as bottoming cycle engines and the fuel economy achieved by using them as bottoming cycles. Present paper is based on results of experiments carried out on small scale Wankel and two-stroke reciprocating engines as air expanders and as steam expanders. A test facility developed at Sussex used for measurements is comprised of a torque, power and speed measurements, electronic actuation of valves, synchronized data acquisition of pressure, and temperatures of steam and inside of the engines for steam and internal combustion cycles. Results are presented for four engine modes, namely, reciprocating engine in uniflow steam expansion mode and air expansion mode and rotary Wankel engine in steam expansion mode and air expansion mode. The air tests will provide base data for friction and motoring effects whereas steam tests will tell how effective the engines will be in this mode. Results for power, torque, and $p-V$ diagrams are compared to determine the change in performance from air expansion mode to steam expansion mode.
\end{abstract}

\section{Introduction and Motivation}

Finding a suitable bottoming cycle for recovery of low grade heat recovered from an internal combustion engine is based on the temperature range of operation and the expected efficiency. Thermoelectric heat recovery provides a relatively cleaner less complicated option, but with very low efficiency. Steam on the other hand has been proven to work in heat recovery cycles with a decent efficiency range. Thomas Newcomen's atmospheric engine, today referred to as the Newcomen engine, was the first practical device that harnessed power of steam to produce mechanical work. James Watt developed it further and steam reciprocating engines have been in use for the last 200 years [1]. The use of steam engines has diminished in the advent of the internal combustion engine and the electric motor. However, steam engines are still being used in various engineering applications, especially in the power generation industry. Small steam expansion engines are in limited use [2]; this is usually because a steam generating system is also required which makes them uneconomical. There have been attempts to use steam expanders as primary power plant of an automobile [3]; however the present work is based on steam small engines as bottoming cycle expanders. There has not been much research done in this area. Particularly, there are no data available on performance of these engines. The work is intended to provide a platform for the development of small steam engines that can be used as bottoming cycle heat expanders. There are various options as steam expanders, for example, vane rotors and microturbines. However, reciprocating expanders and Wankel engines are readily available as small engines that can be converted into steam expanders. The range of the engines in the study has been limited by the size and power that can be mounted on the test apparatus, a table-top dynamometer. Essentially, the rage has been restricted to less than $20 \mathrm{cc}$ cylinder capacity. The primary parameters of the two engines that have been used in the study are listed in Table 1.

1.1. The Rankine Cycle. The steam engine generally operates on the Rankine thermodynamic cycle. Rankine cycles [4] have been widely used in both prime movers and bottoming 
TABLE 1: Engine data.

\begin{tabular}{lcc}
\hline Engine & $\begin{array}{c}\text { Four stroke } \\
\text { reciprocating } \\
\text { engine }\end{array}$ & $\begin{array}{c}\text { Wankel rotary } \\
\text { engine }\end{array}$ \\
\hline Model & OS 32 SX & OS 49 PI \\
Bore $(\mathrm{mm})$ & 19.5 & N/A \\
Stroke $(\mathrm{mm})$ & 17.5 & $\mathrm{~N} / \mathrm{A}$ \\
Capacity $(\mathrm{cc})$ & 5.23 & 4.97 \\
Compression ratio & $10: 1$ & $7: 1$ (approx.) \\
\hline
\end{tabular}

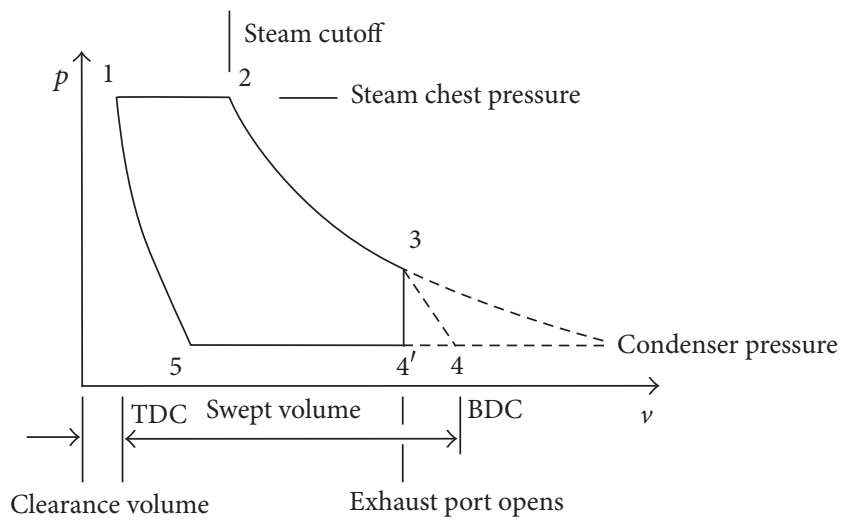

FIgURE 1: Rankine cycle reciprocating expander $P-V$ diagram.

cycle expanders. The reciprocating Rankine cycle has been used in locomotives, ships, and stationary engines. Rotary expanders, primarily, steam turbines, are used in power generation. The use of rotary engine has been restricted by the optimum operating range it offers in comparison to the wide range offered by the reciprocating engine. The use of the steam expander used in this study is mainly aimed as a directly coupled engine that can operate in sync with an internal combustion engine. A reciprocating engine offers similar torques power characteristics to an IC engine. The other main advantage is the availability of small engines that can be converted into steam expanders.

1.1.1. Rankine Cycle with a Reciprocating Expander. A reciprocating Rankine cycle shown in Figure 1 is explained by the following steps:

(1-2) Admission of steam at steam chest pressure.

(2-3) Expansion of steam until the exhaust port is open.

$\left(3-4^{\prime}\right)$ Blow down of the steam to condenser pressure.

(4-5) Exhaust of steam until the exhaust port is closed.

(5-1) Compression of steam left in the cylinder.

The work and heat for the cycle can be found done by obtaining the specific enthalpies $h_{n}$, where $n$ refers to steps in Figure 1 . The theoretical work by the cycle is given by $h_{2}-h_{3}$ and the heat supplied is given by $h_{2}-h_{1}$. The efficiency is given by

$$
\eta=\frac{\left(h_{2}-h_{3}\right)}{\left(h_{2}-h_{1}\right)}
$$

The pump work is neglected as it is small compared to the heat in. Reciprocating steam expanders were the most common type of expanders, known for their high torque and simple operation. These are mostly used as marine and old locomotive prime movers. The speed achievable from large steam engines is limited. Uniflow and counter-flow arrangements are possible with reciprocating expanders [1]. However, the valve arrangements become more complex with counter-flow arrangement [5]. Reciprocating engines are perceived to be easier to implement than Wankel engines [6].

1.1.2. Rotary Steam Engines. Steam turbines are efficient devices, but the range of operation is limited, hence not very suitable for automotive applications. The major attraction of the turbine cycle is the high overall efficiency in operation. However the flexibility of operation outweighs the efficiency factor and makes the reciprocating Rankine cycle more practical. In addition, the ability to cater to fluctuating torque and velocity conditions of the reciprocating cycle makes it the preferred device for automotive applications. Nevertheless, if the energy developed in a turbine is converted into electricity and used to drive an electric motor it leads to a practical solution for hybrid vehicles [7].

An intermediate solution is the Wankel rotary expander [8]. Wankel engine offers some advantages of both the turbine cycle and the flexibility of the reciprocating engine [9, 10]. Micro-Wankel engines can be fabricated with improved fabrication technology [11]. Attempts have been made to correctly emulate the operation of the Wankel engine [12], but the current application is using steam as the working fluid without internal combustion. Figure 2 shows the theoretical Rankine cycle and the pressure volume diagram of a Rankine cycle.

1.2. Waste Heat Recovery. The major attraction of Rankine cycle [13] today is its applicability in the waste heat recovery systems [12]. In power generation, Rankine turbines are driven by steam generated through waste heat recovery. Use of reciprocating engines in waste heat recovery systems is seldom. On the other hand, use of rotary steam engines in small scale applications is not common. Ability of Rankine cycle to operate on low grade heat sources such as steam makes it attractive to employ in a bottoming cycle [14]. Two main types of expanders have been applied in Rankine cycle applications that are of two types: first one is the velocity type, such as axial turbines and radial-flow turbines; the other is positive displacement type, such as scroll expanders, screw expanders, piston expanders, and rotary vane expanders [15]. These expanders feed off a steam reservoir courtesy of heat recovery in a bottoming cycle $[16,17]$. 

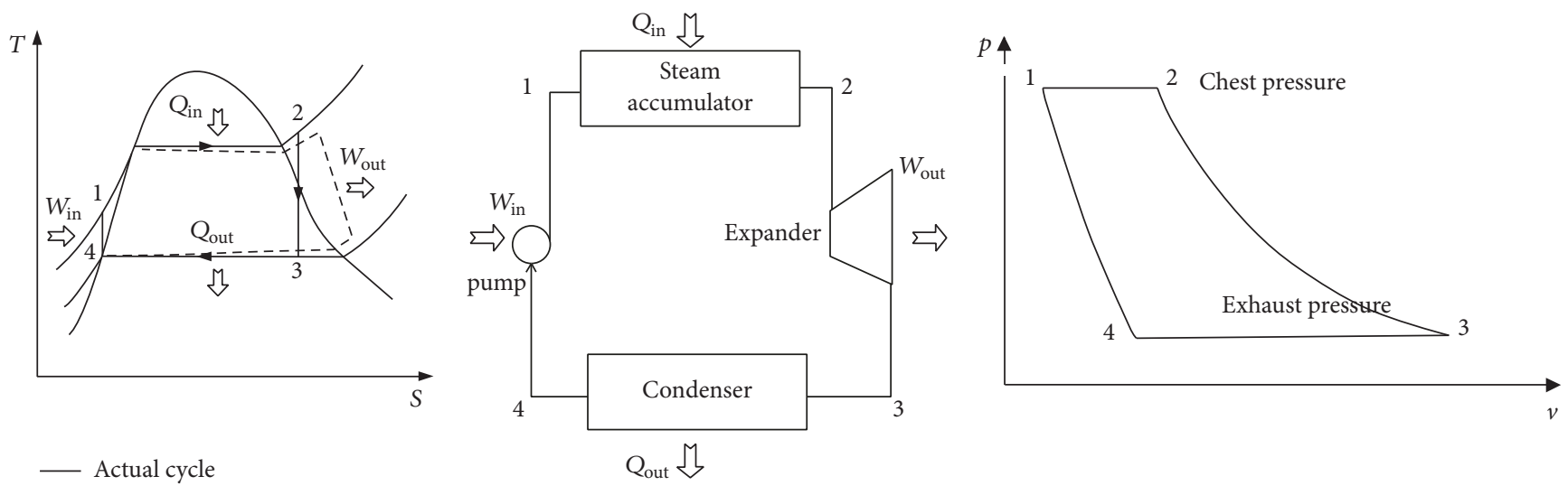

- Actual cycle
-- Idealcycle

Figure 2: A simple Rankine cycle and Wankel Rankine expander $P$ - $V$ diagram.

\section{Experimental Setup}

The experimental setup consists of a dynamometer, a data acquisition system controlled by LabVIEW software, a steam/air supply, and a condenser unit. The sensor inputs are fed to the system through a multichannel data acquisition card. Figure 3 shows the components of the system and how they are linked.

2.1. The Dynamometer. Testing of small scale engines offer the advantages of portability, less instrumentation, low space costs, and flexibility. However there are no readily available dynamometer setups for testing small engines. Hence, a small scale dynamometer facility pictured in Figure 4 had to be developed to mount the small engines for testing. The dynamometer was derived from a model makers' lathe and the drive train was modified to absorb power and to motor when necessary. The engine output shaft is mounted inline with the lathe shaft. Torque transducer arrangement connects the engine output shaft and the lathe shaft. A $400 \mathrm{~W}$ DC motor drives the main shaft that can also absorb power. The end of the drive shaft is fitted to a pulse encoder that generates three pulse streams, namely, (i) pulse per revolution ( $\mathrm{ppr}$ ), (ii) pulse per revolution $-90^{\circ}$ (directional indicator), and (iii) pulse per crank angle degree (pcd).

The engines used were modified model hobby engines manufactured by OS (Japan). The following data are available of the engines used.

For the use as steam expanders, the inlets and exhausts had to be modified to induct and exhaust steam. The engine heads were modified to accommodate for steam connections.

Figure 4 shows a schematic of how the steam induction and exhaust connections and valves are configured. The picture shows the configuration of the ports controls and steam in and out. The arrangement is the same for the rotary engine except for the fact that the rotary engine has two inlet valves and two exhaust valves. The opening and closing of the rotary engine valves take place without electronic control.

2.2. Steam Expanders. Steam expanders are available in the form of reciprocating expanders and rotary expanders. In the

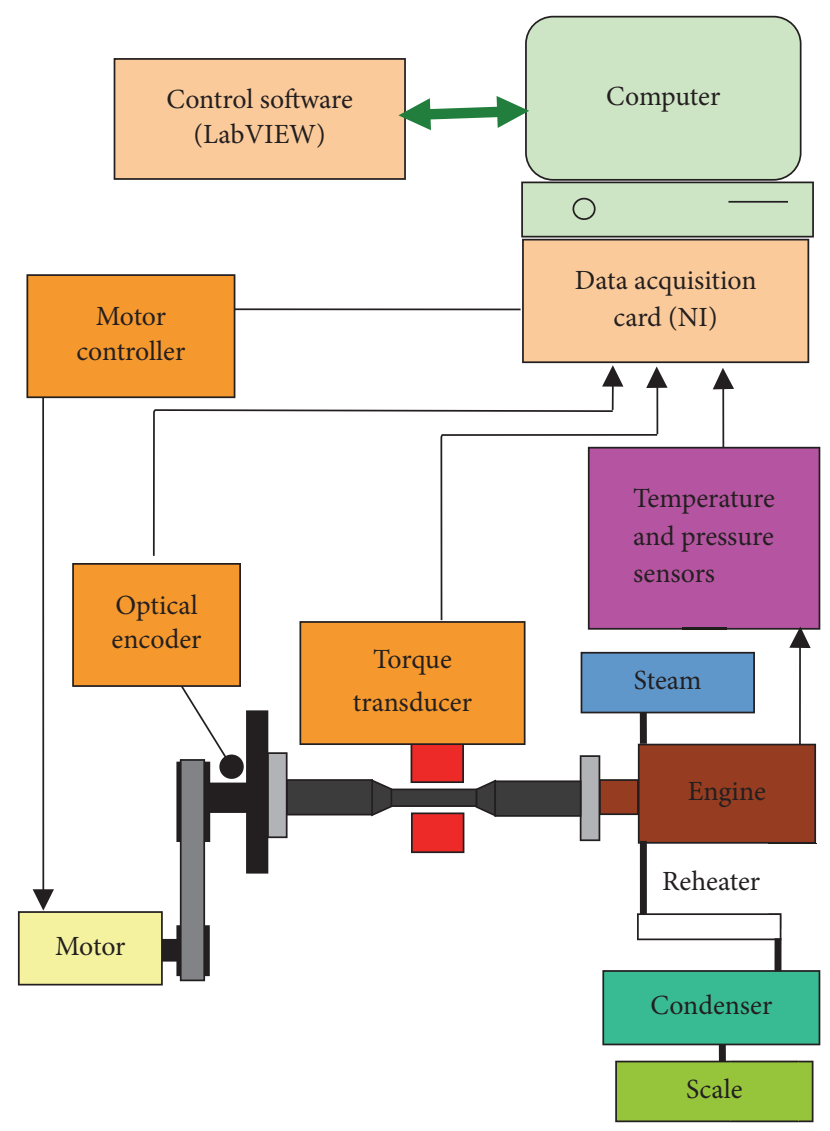

FIgURE 3: The experimental setup.

present context uniflow reciprocating expander and a rotary Wankel engine are tested.

2.2.1. Reciprocating Steam Engine. A two-stroke internal combustion engine has been modified to accommodate steam admission through an electrically operated overhead valve. An automotive fuel injection valve has been modified for the purpose. The steam enters through an electrically 


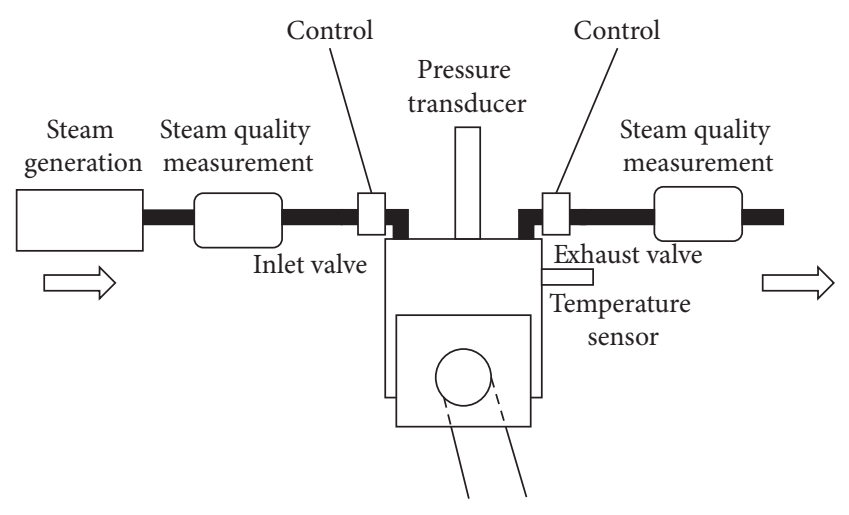

FIGURE 4: Schematic of the cylinder arrangement.

operated inlet valve and exhausts through a port at the BDC. The timing of steam admission is critical for propulsion. The valve timing was set to $3^{\circ} \mathrm{BTDC}$ and kept for $100^{\circ}$ for the inlet valve. Exhaust takes place through a $6 \mathrm{~mm}$ long $25 \mathrm{~mm}$ wide port before BDC.

2.2.2. Valve Arrangement for the Two-Stroke Reciprocating Engine. Two pulse streams are utilized from the optical encoder by the data acquisition card, the pulse per revolution (ppr), and the pulse per crank angle degree (pcd). The ppr pulse is aligned with the top dead centre of the piston. LabVIEW software that controls the actuation of the valve and samples the data for storage uses the pcd pulse as a source of clock ticks and ppr pulse as a trigger for an output pulse. The timing of the valve actuation is synchronized with pcd pulse and is variable.

2.2.3. Wankel Steam Engine. A modified small scale internal combustion Wankel engine is used as a steam expander. The flow through the Wankel engine is uniflow, and continuous generation of torque is available with three expansions per cycle of the rotor. The $P-v$ diagram for a Wankel Rankine cycle is not available in the literature. However, Figure 9 shows a pressure plot drawn against the crank angle as that is more appropriate than a $P-v$ diagram. A $5 \mathrm{~cm}^{3}$ model Wankel engine has been modified to run as a Wankel steam expander. There are two inlet ports and two exhaust ports. They were changed to obtain optimum performance. The inlet port is at $20^{\circ}$ to the original line of the engine and the exhaust valves have been changed to a side exhaust arrangement as in Figure 5.

2.3. Instrumentation and Measurements. The engine is supplied with air or steam as appropriate and the fluid flow rate is controlled electronically. Measurements were taken at two set pressures of 7 bars and 15 bars for air and steam, respectively. Pressure, temperature, torque, speed, and pulse signals are fed through the National Instruments (NI) data acquisition card to the computer. Communication with the scales takes place via an RS232 connection. All the data acquisition and control are performed using LabVIEW software. The sampling was triggered by the pulse per crank angle degree (pcd) pulse from the optical encoder.

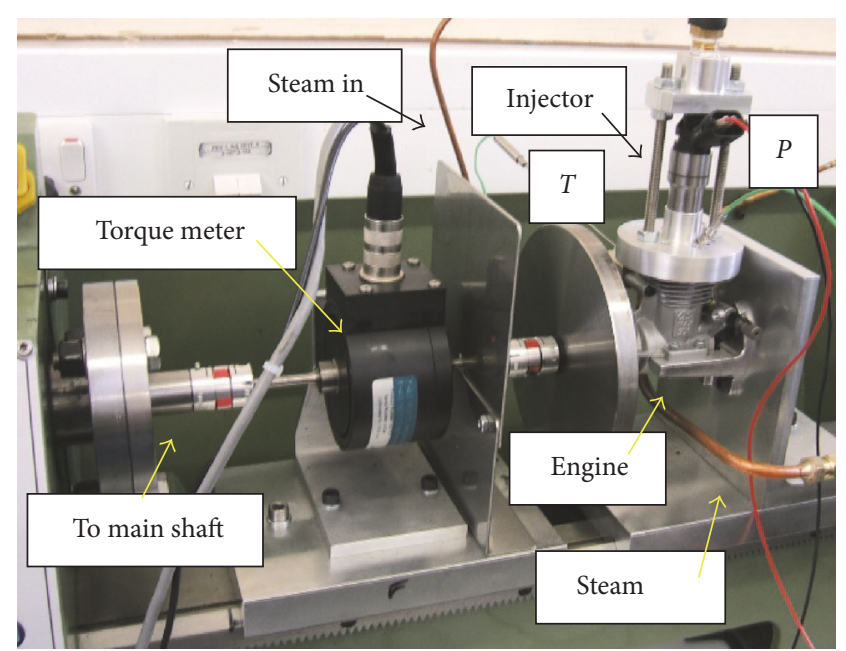

FIgURE 5: The dynamometer with the reciprocating engine mounted; $P=$ pressure sensor; $T=$ thermocouple.

2.3.1. Pressure. Pressure measurements were acquired for the engine inlet, engine outlet, inside of the cylinder, reheater inlet, and reheater outlet via piezoelectric pressure sensors.

2.3.2. Temperature. The temperatures at engine inlet, engine outlet, inside of the engine, reheater inlet, and reheater outlet were acquired using $K$ type thermocouples.

2.3.3. Torque and Speed. Torque and speed are obtained via the inline torque transducer, from these readings power is given by

$$
P=2 \pi N T
$$

2.3.4. Mass Flow Rate. The condensate from the engine is collected in a vessel on the electronic scales. The incremental weight against time gives the mass flow rate.

2.3.5. Steam Quality. The analysis of the steam quality of the exhausted steam required a new device setup. The steam coming out of the engine is wet and hence, the pressure and temperature alone would not give the steam condition. A reheater section is fitted to the exhaust pipes which brings the steam to a superheated condition at which the pressure and temperature alone would be able to give the state of the steam. Figure 6 shows the temperature and pressure tapping point and Figure 7 shows the steam quality analyzer.

Pressure and temperature sensors are placed at the input to the SQA (ri) and the exit point from the SQA (re). The readings are used to obtain the specific enthalpy $h_{\text {re }}$ at re from steam tables. Then, $h_{\mathrm{ri}}$ is given by

$$
h_{\mathrm{re}}-h_{\mathrm{ri}}=\frac{V I t}{M}
$$

where $M$ is the mass of water collected in time $t$. VI is the recorded voltage and current used by the reheater section. The most important measurements of the system are the pressures and temperatures of the inlet, outlet, and inside of 


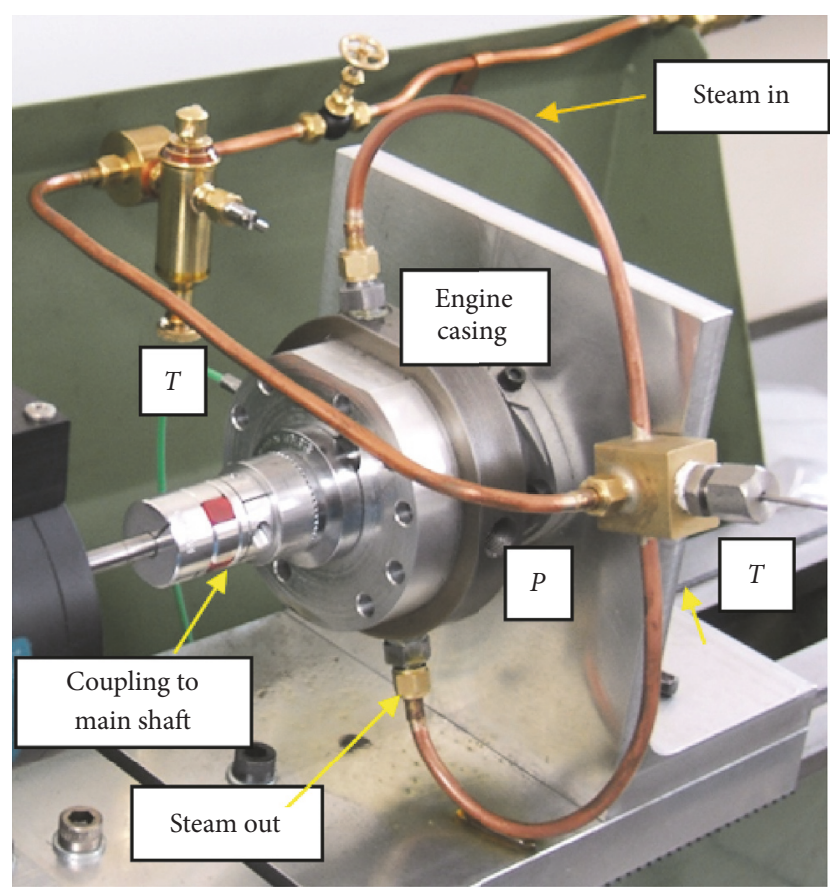

Figure 6: The Wankel engine; $P=$ pressure sensor; $T$ = thermocouple.

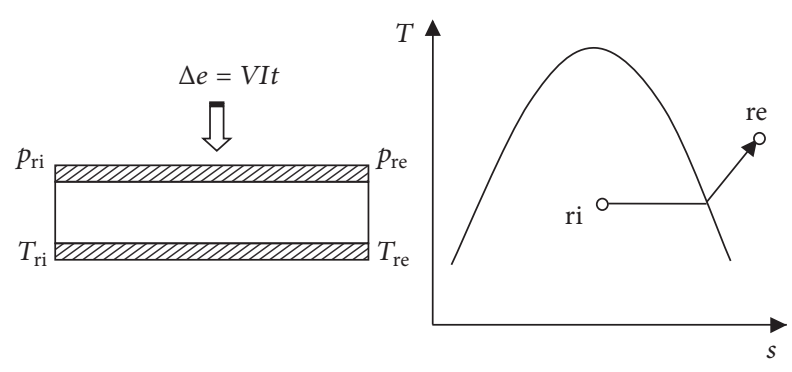

FIGURE 7: Steam quality analyzer (SQA).

the engine. These measurements can be used to determine the inlet and outlet conditions of the steam and hence to develop an energy balance.

2.3.6. Engine Efficiency. Efficiency of the engine can be calculated with the heat input values and the power developed by the engine.

\section{Engine Test Results}

Figures 10 and 13 show the power curves for different inlet pressures of the engine. The optimum supply pressure lies around 30 bars that has been confirmed by previous Prasad [7]. Pressures above this range will have a negative effect which is explained by a close analysis of the Molier diagram for water. Saturated steam at pressures above 30 bars stores less enthalpy than steam at 30 bars. Peak to peak measurements of pressures have been taken and the data are referred against supply pressure of zero. The readings are

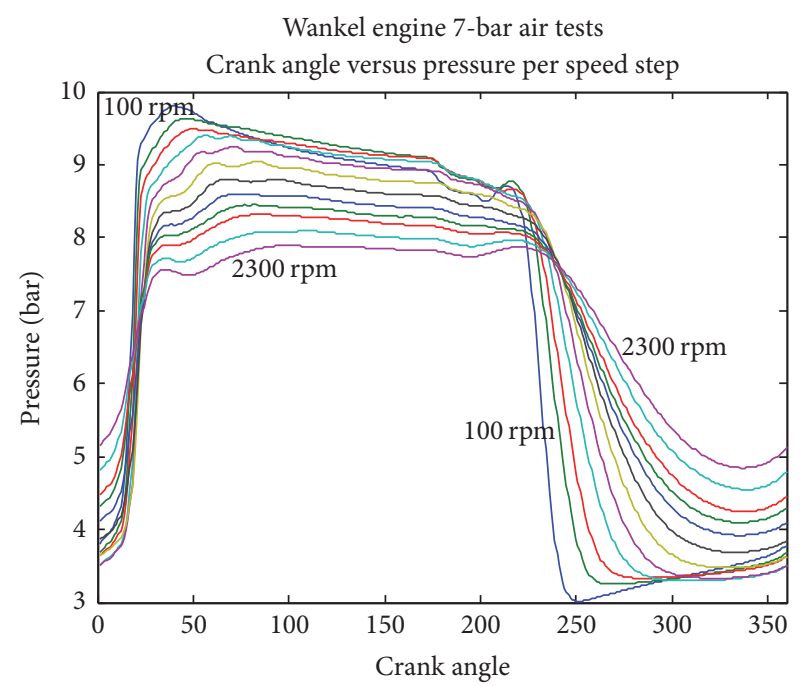

FIgURE 8: Wankel engine 7-bar air tests, crank angle versus pressure.

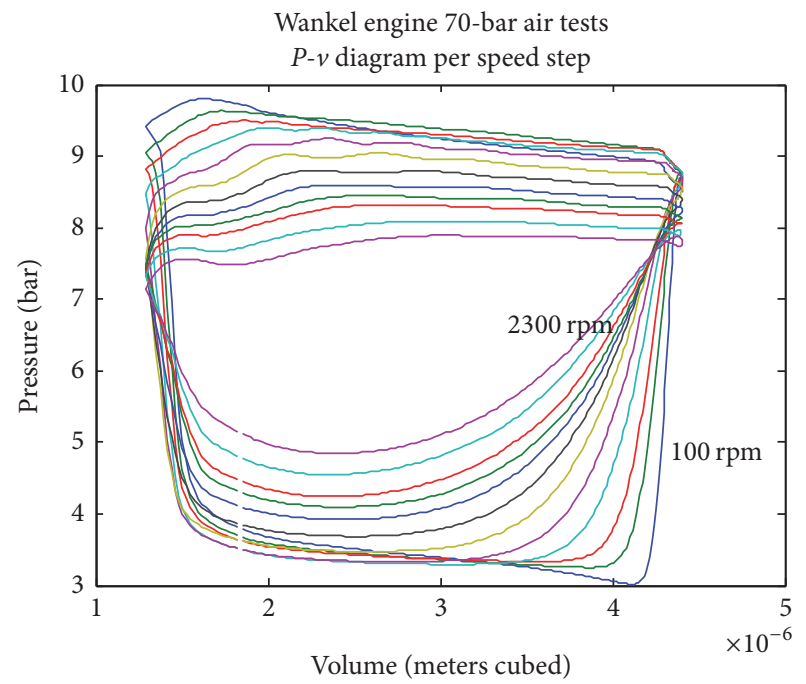

FIGURE 9: Wankel engine 7-bar air tests, $p$ - $V$ diagram.

plotted after taking the offset into account and reflect the absolute value.

3.1. Air Tests on Wankel Engine. Air test data was acquired for rpm values 100, 200, 300, 500, 700, 900, 1100, 1300, 1500, 1700,2000 , and 2300. The pressure volume diagram for air tests for the Wankel engine is given in Figure 9 for 7-bar air. The pressure-crank angle relationship is shown in Figure 8. When the supply pressure is low, substantial motoring takes place and is illustrated by the negative pressures in the $P-v$ diagram.

Air test data was acquired for rpm values $200,300,500$, 900, 1300, and 1700 .

3.2. Steam Tests on Wankel Engine. Steam tests were done at 10-bar supply pressure and 15-bar supply pressure. 15-bar results are shown here as 15 bars was the highest pressure 


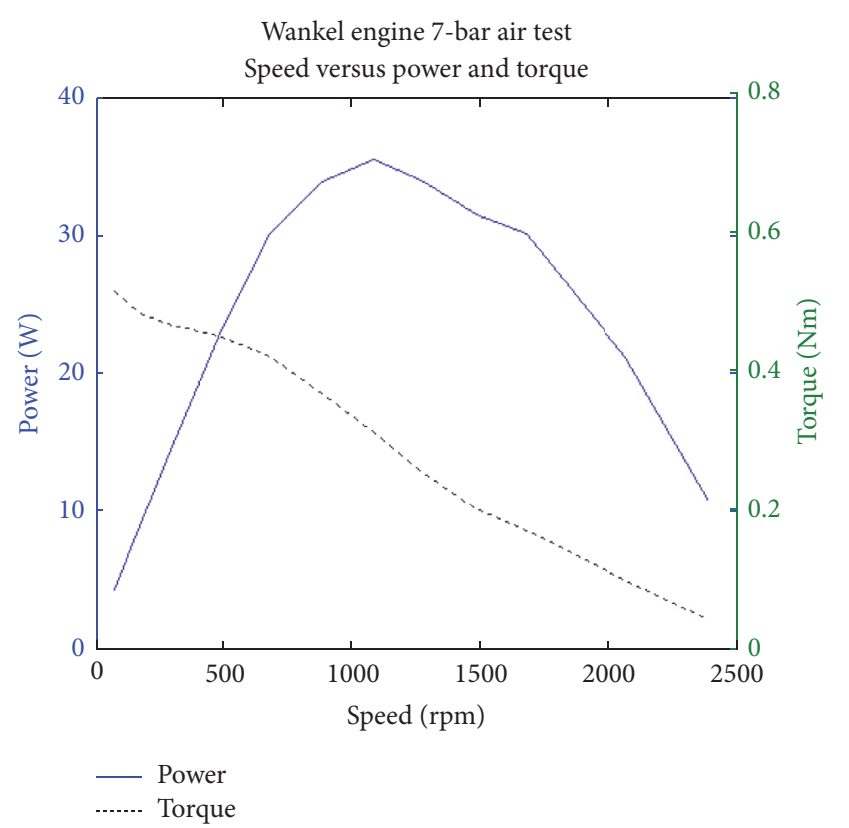

FIGURE 10: Wankel engine power and torque for 7-bar air.

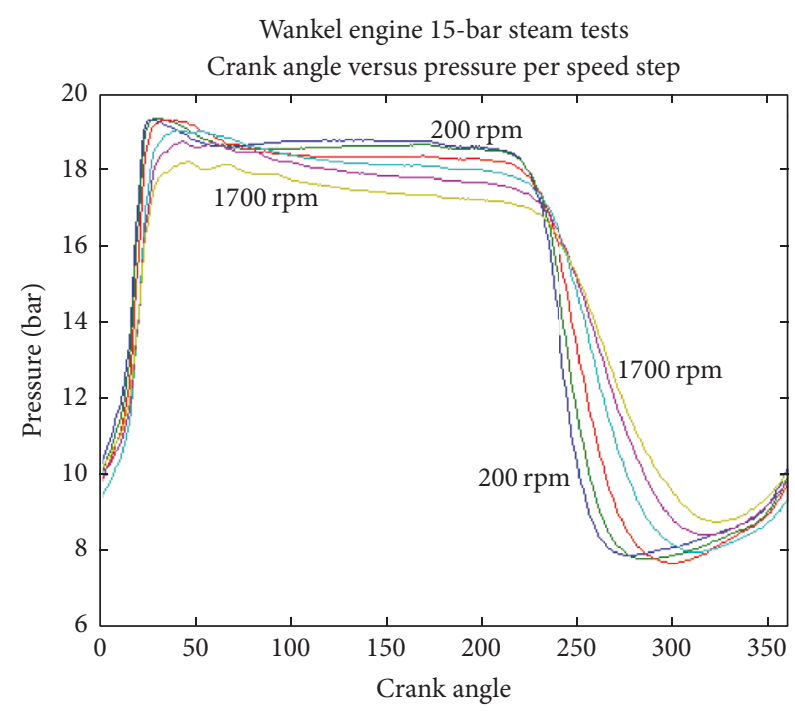

FIGURE 11: Wankel engine 15-bar steam tests, crank angle versus pressure.

at which data were logged as in Figures 11 and 12. Tests were done with a pressure regulated steam supply off an industrial boiler. The major observation expected of the pressure characteristics of the steam tests is the effect of expansion.

3.3. Air and Steam Tests on Reciprocating Engine. Measurements were taken on the expansion of steam at 10 bars in the reciprocating engine. Data was obtained only at $200 \mathrm{rpm}$ to $800 \mathrm{rpm}$. This is deemed appropriate as the engine is expected to run at a lower speed than the IC engine. The shape of the $P-v$ diagram is significantly consistent with the theoretical

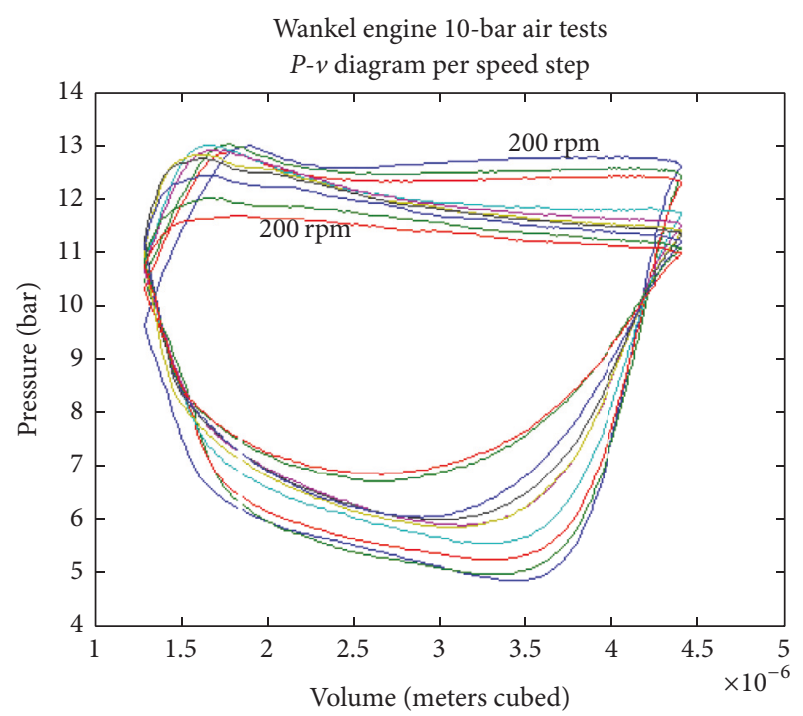

Figure 12: Wankel engine 15-bar steam tests, $p$ - $V$ diagram.

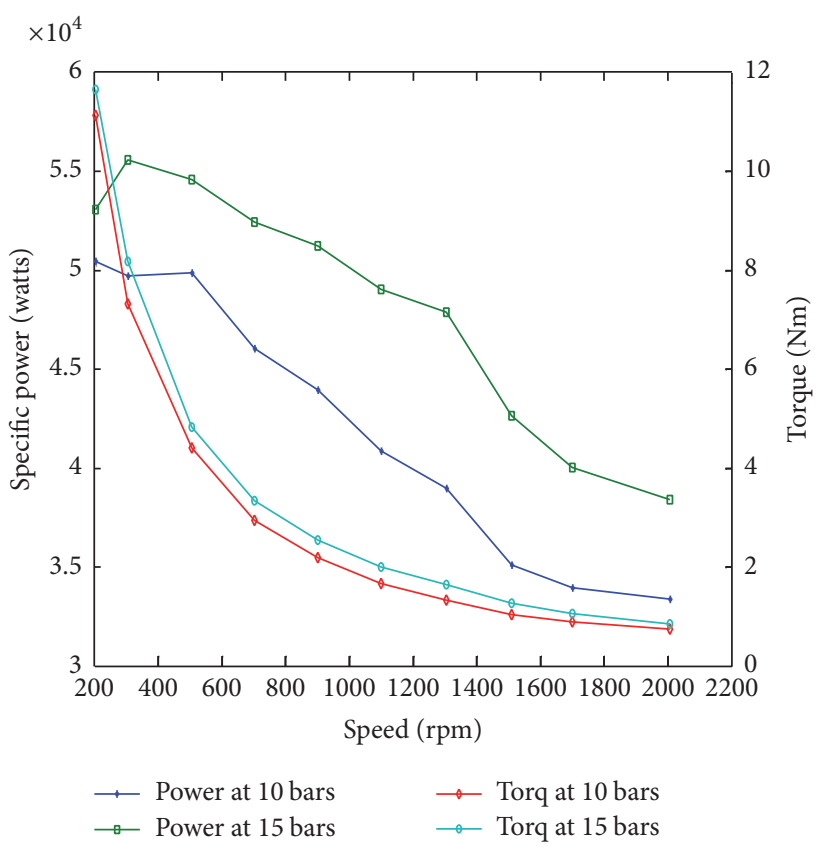

FIGURE 13: The Wankel engine power and torque for 10-bar and 15bar steam.

diagram as shown in Figure 14. Specific power and torque characteristics are shown in Figure 15 at 10 bar.

The power torque diagram is also pretty impressive and is of expected shape except for the readings at $400 \mathrm{rpm}$. However, the general behavior is as expected.

Table 2 summarizes the results obtained for the air and steam tests. Air test diagrams are not shown in here as they were done only for validation purposes.

3.4. Analysis of Results. The $P-V$ diagrams for air and steam expansion in rotary and uniflow reciprocating engines are presented. The $p-V$ characteristics of the Wankel expander 


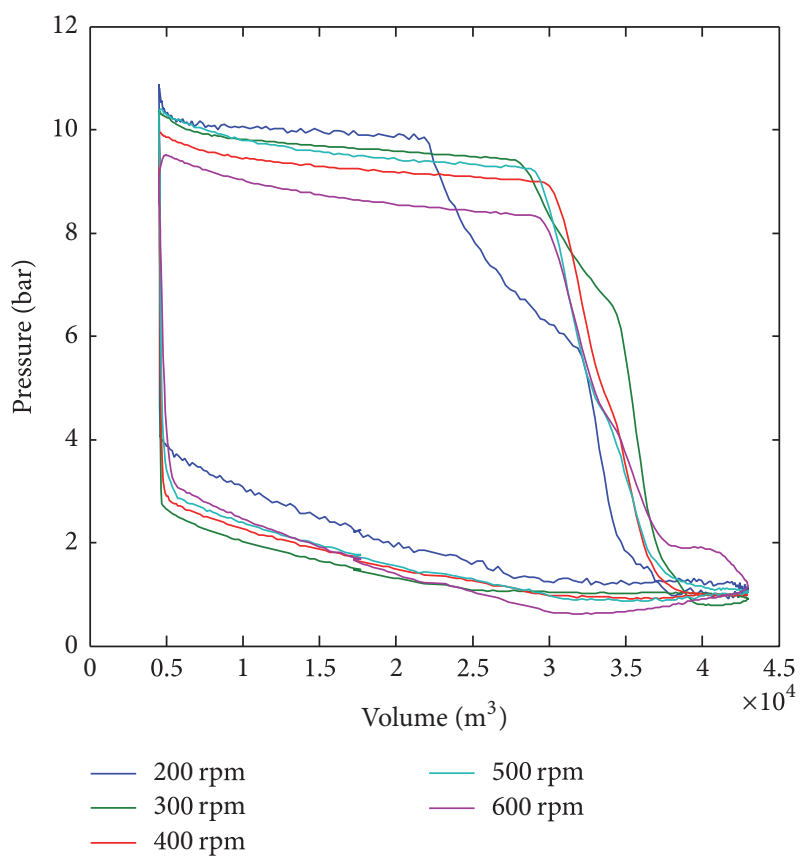

Figure 14: $P-v$ diagram, reciprocating engine, 10-bar steam, with solenoid inlet valve.

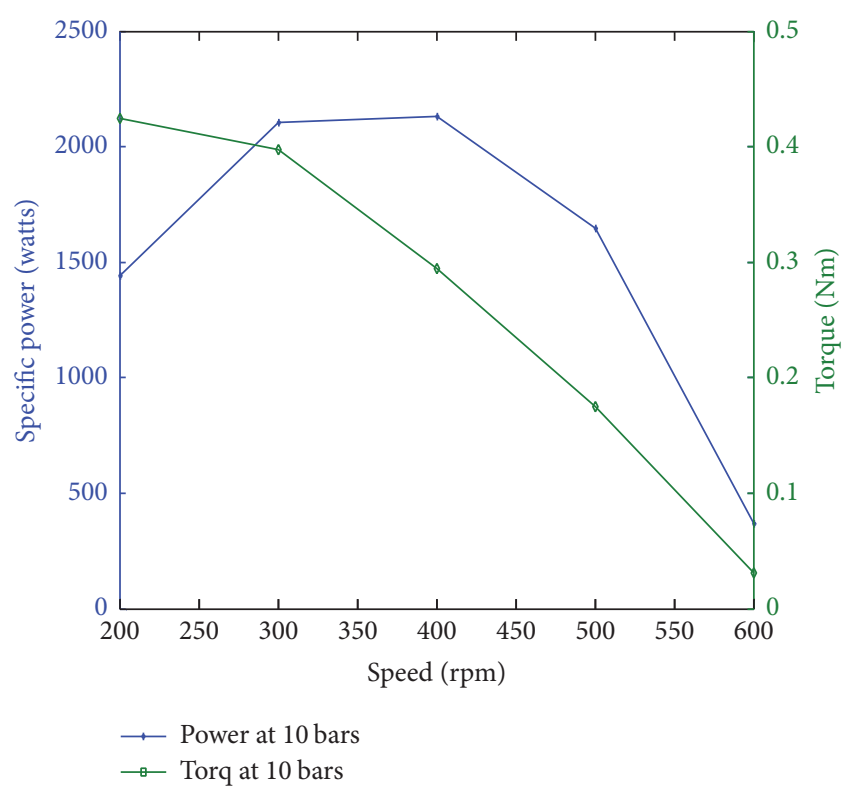

FIGURE 15: Specific power and torque, reciprocating engine, 10-bar steam.

are shown in Figures 9 and 12. The pressure against crank angle diagram for the Wankel engine shows a clear expansion of steam at low speeds. The expansion effect diminishes with higher speeds. This is better explained by the torque curve for the same. The torque developed is high at lower speeds. The clear reason for this behavior is the time taken by steam to expand [18]. The expansion of steam is much higher than that of air and the energy release is clearly visible. The maximum power curve for air gives a maximum at around $1000 \mathrm{rpm}$
TABle 2: Performance comparison of the engines.

\begin{tabular}{lcc}
\hline & Wankel engine & Reciprocating engine \\
\hline Maximum power (air) & $1400 \mathrm{~W} / \mathrm{kg}$ & $2800 \mathrm{~W} / \mathrm{kg}$ \\
Maximum torque (air) & $0.80 \mathrm{Nm}$ & $0.38 \mathrm{Nm}$ \\
Maximum power (steam) & $5550 \mathrm{~W} / \mathrm{kg}$ & $2600 \mathrm{~W} / \mathrm{kg}$ \\
Maximum torque (steam) & $11.65 \mathrm{Nm}$ & $0.45 \mathrm{Nm}$ \\
\hline
\end{tabular}

whereas this for steam is at around $400 \mathrm{rpm}$. This shows the higher expansion rate of air. The steam coming out of the engines being wet means that there is a phase change in the expansion process. The phase change process is slower than the direct expansion of air. However, when these are used as bottoming cycles it is necessary to have a reduction ratio of around $10: 1$ to run parallel with an internal combustion engine. This is due to the fact that optimum operating rpm rage of steam expanders lies within 100 to 250 whereas IC engines run optimum around $2000 \mathrm{rpm}$.

The slow operation of steam does not make it a less favored candidate as a bottoming cycle expansion medium. It allows the steam to build up and consumes at a slower rate as well. Once properly geared this should supply enough boost torque through the drive train.

In addition to the results obtained from testing, certain issues were highlighted during testing. The quality of the steam is critical to the prolonged operation of the engine [19]. A closed cycle system is hence preferred to an open cycle. The steam admission valve design is critical in the injection of steam into the cylinder. A mechanical device may be more robust, at least for the parts that are in contact with steam. The small engines may suffer from them being small, so that the endurance of the engines is low. It is anticipated to obtain better endurance from those engines.

Proper scaling can be done when all the simulation and test data are available for the engines.

\section{Conclusion and Future Work}

Performance measurements have been carried out to predict the suitability of small engines as steam expanders. The engines have been modified to suit steam expansion. The operating speed range of steam is much lower than that of internal combustion engine. This prevents us making direct comparisons. The air tests provide a much comparable set of data for the expanders. Comparing the maximum power and torque data of the two engines it is evident that the Wankel engine provides a much better device as an expander.

The major aim of this work is to measure the suitability of Rankine steam cycle as a heat recovery bottoming cycle and compare the performance of two engine types, the reciprocating engine and the Wankel engine. The power and torque characteristics shown for small engines make them very suitable for the purpose. The work involves the development of complete Rankine bottoming cycle including controls. This includes the heat recovery system and thermal control of the IC engine and the steam cycle. Endurance tests need to be done to steam engines developed to check the 
longevity $[3,20]$. Separate work is being done to develop the control strategies and techniques.

The scaled down dynamometer developed to measure the performance of the engine provides a very useful tool for scaled model testing. The torque and power curves obtained could be scaled up for a full size engine.

The valve timing for the two-stroke engine is a sensitive factor in the engine performance. Small engines do not allow a great deal of flexibility for us to change this. Only the timing can be changed with electronic triggering. In a full scale engine, much larger valves can be employed and there will be room for finer adjustment.

The tests revealed a number of areas for improvement. The reliability of the engines could be a major issue. Use of steam oil that improves reliability is possible with a closed cycle. In an open cycle this becomes an emission issue as it will be released to the atmosphere.

Using small engines to determine engine characteristics supplies a basis for designing medium scale steam engines. The finding can be backed up by simulations once a complete set of data are available. The authors intend to do further testing on a larger engine with a heat recovery system attached to an internal combustion engine.

4.1. Engine Simulations. The results can be compared with results obtained from $1 \mathrm{D}$ engine simulation results. Values can be obtained for air expansion and an optimum operating point can be obtained. No simulation results are presented at this moment. Initial comparisons which are not presented here, however, suggest that the measurements can be backed by simulations. These results show that steam expanders, even at small scale, are suitable devices for heat recovery bottoming cycles. A full set of simulations as described above can be used for scaling up of the findings for commercial engine applications. The motoring effect and friction are expectedly high in small engines as a percentage. However, they provide concept proving valid statistics.

\section{Conflicts of Interest}

The authors declare that there are no conflicts of interest regarding the publication of this paper.

\section{Acknowledgments}

The authors would like to extend their gratitude to the EPSRC for funding the work [Grant no. GR/T19810/01], Professor R. K. Stobart, the principal investigator, Ian Wallis and Barry Jackson of University of Sussex for their support in conducting the research, and Spirax Sarco Ltd., UK, for providing steam facility and support.

\section{References}

[1] P. W. B. Semmens and A. J. Goldfinch, How Steam Locomotives Really Work, Oxford University Press, 2000.

[2] G. Ferrara, G. Manfrida, and A. Pescioni, "Model of a small steam engine for renewable domestic CHP (combined heat and power) system," Energy, vol. 58, pp. 78-85, 2013.
[3] S. Jakuba and J. A. McGeehan, "Component development of automotive reciprocating steam expanders," SAE Prepr, SAE Technical Paper, 1975.

[4] S. Zhu, K. Deng, and S. Qu, "Energy and exergy analyses of a bottoming rankine cycle for engine exhaust heat recovery," Energy, vol. 58, pp. 448-457, 2013.

[5] M. Badami and M. Mura, "Preliminary design and controlling strategies of a small-scale wood waste Rankine Cycle (RC) with a reciprocating steam engine (SE)," Energy, vol. 34, no. 9, pp. 1315-1324, 2009.

[6] G. Bidini, A. Manuali, and S. Saetta, "Reciprocating steam engine power plants fed by woodwaste," International Journal of Energy Research, vol. 22, no. 3, pp. 237-248, 1998.

[7] S. B. Prasad, "Steam engine characteristics and theoretical performance," Energy Conversion and Management, vol. 34, no. 12, pp. 1323-1333, 1993.

[8] G. A. Brown and D. A. Bowlus, "Rotary piston expander engine," in Proceedings of the 11th ICECEC, pp. 1187-1191, 1976.

[9] O. Badr, S. Naik, P. W. O'Callaghan, and S. D. Probert, "Expansion machine for a low power-output steam Rankine-cycle engine," Applied Energy, vol. 39, no. 2, pp. 93-116, 1991.

[10] J. D. Wade, R. M. Tompkins, G. A. Brown, and G. J. Silvestri, "Rotary expander engine testing and analysis," in Proceeding of 18th IECEC, pp. 636-641, 1983.

[11] C. H. Lee, K. C. Jiang, P. Jin, and P. D. Prewett, "Design and fabrication of a micro Wankel engine using MEMS technology," Microelectronic Engineering, vol. 73-74, pp. 529-534, 2004.

[12] L. Tartakovsky, V. Baibikov, M. Gutman, M. Veinblat, and J. Reif, "Simulation of Wankel engine performance using commercial software for piston engines," SAE Technical Papers, vol. 4, 2012.

[13] B. Fu, Y. Lee, and J. Hsieh, "Experimental investigation of a 250$\mathrm{kW}$ turbine organic rankine cycle system for low-grade waste heat recovery," International Journal of Green Energy, vol. 13, no. 14, pp. 1442-1450, 2016.

[14] R. Stobart and R. Weerasinghe, "Heat recovery and bottoming cycles for SI and CI engines-A perspective," SAE Technical Papers, no. 0662, 2006.

[15] G. Qiu, H. Liu, and S. Riffat, "Expanders for micro-CHP systems with organic Rankine cycle," Applied Thermal Engineering, vol. 31, no. 16, pp. 3301-3307, 2011.

[16] F. J. Bayley, "The saturated liquid reservoir for energy storage in hybrid vehicles," in Proceedings of the IMechE Automobile Division SoUthern Centre Conference on Total Vehicle Technology Challenging Current Thinking, September 2001.

[17] R. Stobart, S. Hounsham, and R. Weerasinghe, "Controllability of vapour based thermal recovery systems in vehicles," $S A E$ International, World Congress, no. 0270, 2007.

[18] W. M. S. R. Weerasinghe, R. K. Stobart, and S. M. Hounsham, "Thermal efficiency improvement in high output diesel engines a comparison of a Rankine cycle with turbo-compounding," Applied Thermal Engineering, vol. 30, no. 14-15, pp. 2253-2256, 2010.

[19] V. Dolz, R. Novella, A. García, and J. Sánchez, "HD Diesel engine equipped with a bottoming Rankine cycle as a waste heat recovery system. Part 1: study and analysis of the waste heat energy," Applied Thermal Engineering, vol. 36, no. 1, pp. 269-278, 2012.

[20] A. Nuvolari, B. Verspagen, and N. von Tunzelmann, "The early diffusion of the steam engine in Britain, 1700-1800: a reappraisal," Cliometrica, vol. 5, no. 3, pp. 291-321, 2011. 


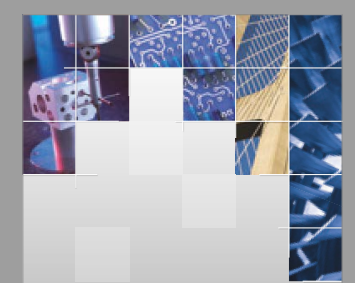

\section{Enfincering}
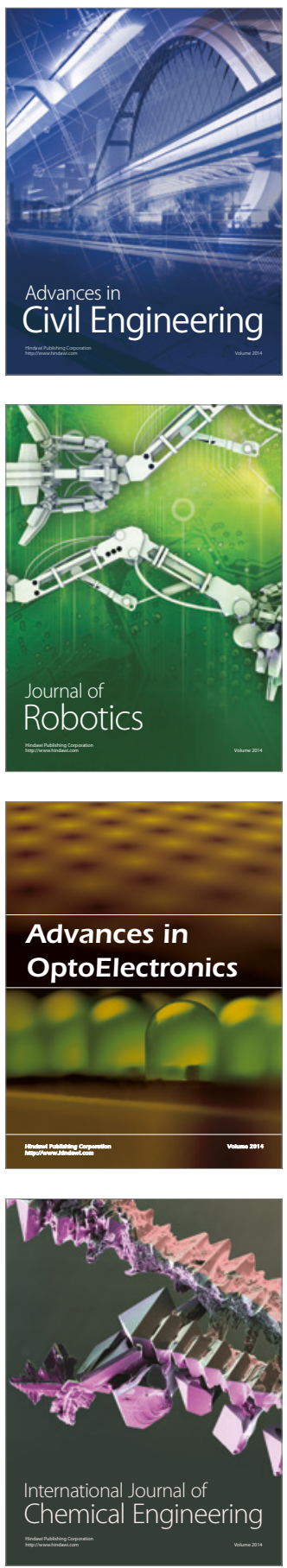

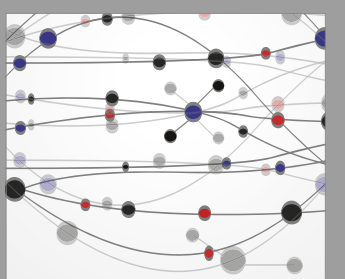

The Scientific World Journal

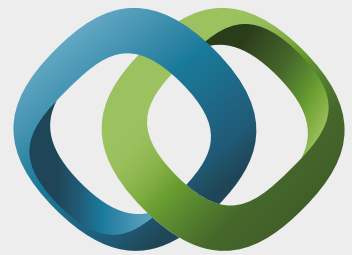

\section{Hindawi}

Submit your manuscripts at

https://www.hindawi.com
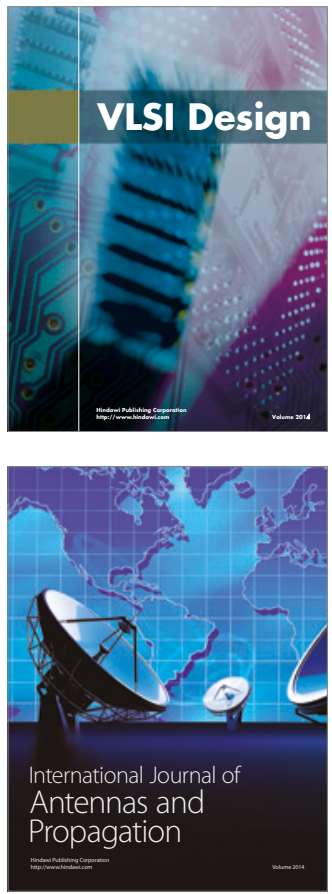

\section{Rotating}

Machinery
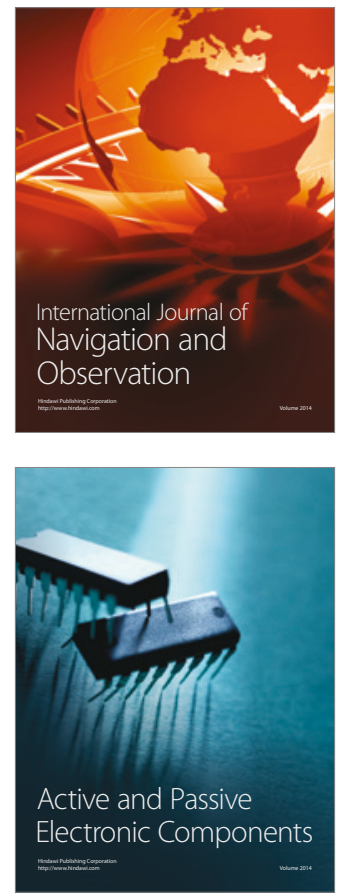
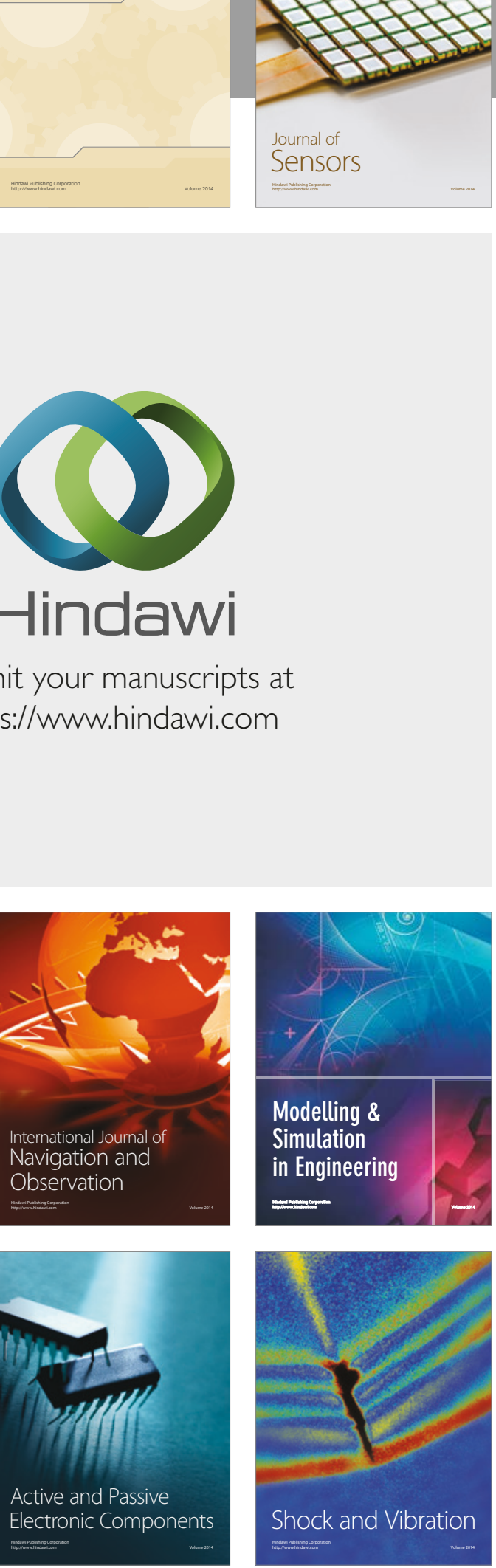
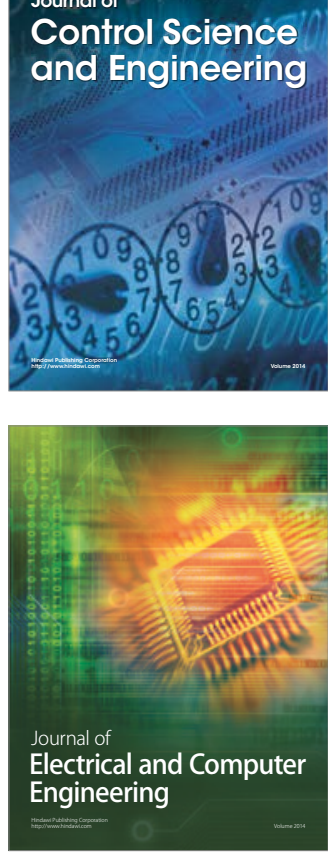

Distributed

Journal of

Control Science

and Engineering
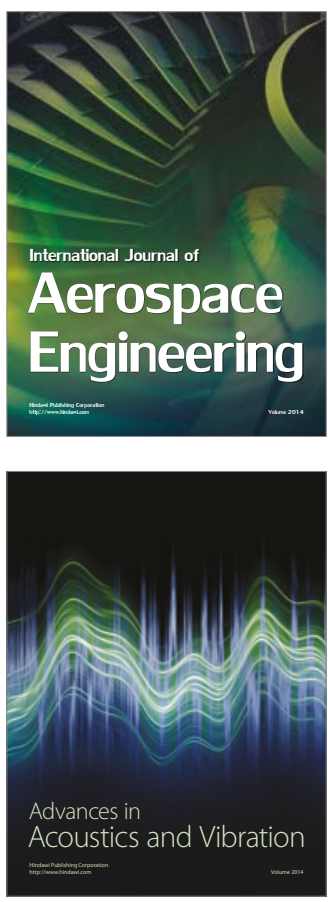

Sensor Networks 